\title{
PYRETO-THERAPY BY INTRAVENOUS T.A.B. VACCINE IN THE TREATMENT OF SULPHONAMIDE RESISTANT GONORRHEA AND NON-GONOCOCCAL URETHRITIS
}

\section{Discussion}

Wing-Commander G. L. M. McElligott congratulated Capt. Nicol on a most painstaking work in which the accompanying charts and analyses were altogether admirable. With regard to results he had treated under fifty cases and his own results were similar to those of Capt. Nicol. He had been particularly struck by Capt. Nicol's suggestion that the results most favourable were those in which further chemotherapy had followed pyretotherapy with T.A.B. vaccine. That had certainly been his own experience; the cases in which there had been real benefit had been those followed by chemotherapy except in arthritis and other metastatic conditions which had almost all immediately benefited. It is suggested that the pyretotherapy in some manner mobilised the antibodies and brought about a state in which the sulphonamides were effective.

DR. A. H. HARKNESS was surprised that it had been necessary to induce fever in so many cases. He considered that fever should not be given unless sulphathiazole had failed, for this drug cured $60 \%$ of the failures after sulphanilamide and sulphapyridine.

He saw no advantage in giving sulphonamides immediately before the fever when drug fastness was complete, but considered it was helpful when drug fastness was partial ; when complete the sulphonamides were not bacteriostatic and interfered with the normal defence mechanism, but when partial there was a bacteriostatic effect, but the final knock-out blow of the disabled organisms by the leucocytes and the cells of the reticulo-endothelial system appeared to be lacking. When fever failed to effect a cure subsequent chemotherapy was always successful. It was not necessary for the fever to correspond with the thermal death time of the gonococcus and he often had good results with fever not higher than $102^{\circ} \mathrm{F}$., provided that this had been delayed for at least three weeks after the onset of the infection. In old infections mild protein shock reactions with only slight pyrexia are occasionally effective.

Capt. Nicol had referred to the coupled or divided dosage used by Nelson and Driver and Ward. Weinberg and Goldstein (I94I) also used divided dosage, but the second injection (which was always higher than the first) was only given if the temperature after two hours was not higher than io ${ }^{\circ} \mathrm{F}$. Their schedule of dosage ranged from 20-2,000 million organisms. Kulchar and Card (I94I) have recently used coupled dosage of $(\mathrm{H})$ antigen prepared from the flagellæ of typhoid bacilli. They claim the systemic reactions are lessened.

$\mathrm{He}$ was surprised that there was no mention of the organisms responsible in the non-gonococcal cases. Staphylococcal urethritis, the most. frequent non-specific urethral infection, invariably reacts to 


\section{BRITISH JOURNAL OF VENEREAL DISEASES}

chemotherapy but often takes at least ten days before improvement is noted, and it is possible that the short intensive courses given by Capt. Nicol were inadequate and led him to believe that so many cases were drug fast. Infections due to Streptococcus Fæcalis appeared to be resistant to sulphathiazole and other sulphonamides.

DR. DAVID NABARRo said that this form of treatment had been used for a considerable time, especially. in neurosyphilis, and better results were obtained if, after the fever had been administered, further chemotherapy was given. Therefore one would expect, as Capt. Nicol had found, to get better results where chemotherapy was given after the fever.

It had been suggested that the fever acted by stimulating the defensive mechanism in the reticulo-endothelial system. Presumably when chemotherapy was instituted later the combined effect was greater than would have been produced by either alone. The nature of the organisms present in the non-gonococcal urethritis was important because it was possible that the treatment which would affect one type of infection would be impotent against another.

DR. F. C. DoBle said that about two years ago he had under his care some cases of gonorrhœa which had proved resistant to sulphanilamide. To one of the more severely ill patients he gave Ducrey bacillus vaccine (Dmelcos) but was unable to raise the temperature above Ior $^{\circ} \mathrm{F}$.; the vaccine used was three years old. On the following day T.A.B. vaccine (50 million bacilli) was given four hourly for three injections. The temperature rose to $105^{\circ} \mathrm{F}$. and the infection cleared up speedily. T.A.B. vaccine was good but he thought that the vaccine of Ducrey's strepto-bacillus (Dmelcos) was more effective and less toxic.

DR. R. MARINkovitch agreed with Dr. Harkness that vaccine therapy should not be employed unless sulphathiazole and local treatment had been given. Unfortunately sulphathiazole was unobtainable. His own standby in arth ritis cases was Arthigon and later Dmelcos. When these became unobtainable he decided to use T.A.B. vaccine and at first gave I c.c. intravenously. The first 20 cases were very ill and all developed Herpes Febrilis, but the therapeutic result was excellent.

Later he gave 0.25 c.c. diluted with 5 c.c. of sterile water, increasing the dosage by 0.25 c.c. according to the febrile response and general condition of the patient. The vaccine he used was Wellcome's preparation, I c.c. containing I,000 million B. typhosus, 750 million B. paratyphosus A and 750 million B. paratyphosus B.

He thought that cases of gonorrhœa resistant to chemotherapy were rare. Cases that have relapsed or showed complications are invariably found in seamen and travellers who have taken tablets irregularly and received no local treatment. The ideal treatment was sulphathiazole and local irrigations, and if the case relapsed even then the patient would be cured in time by ordinary methods without fever therapy. He congratulated Capt. Nicol on his excellent contribution to the subject, but felt that the cure rate achieved was a little disappointing. Perhaps the low dosage used was the cause.

Lieut.-Colonel A. J. King said that he had been surprised to hear of these experiences with massive dosage of T.A.B. vaccine, because, before Capt. Nicol took up the divided dose method, very large doses 


\section{PYRETO-THERAPY}

were being used, 700 million organisms in one dose intravenouslyand, as shown, the results were inferior to those obtained with smaller divided doses. The temperature peaks were lower, the duration of temperature shorter, the patient was made more ill and the results were less satisfactory. In a few cases good results followed massive dosage, but on the whole the results were not good, and his recollection was some patients were made worse and had even developed complications.

With regard to the non-gonococcal cases, information on the nature of the bacteria present would have been instructive, but in a busy clinic culture investigation took time and had not been carried out.

He thought that Capt. Nicol's results should be assessed in two ways, first as regards the immediate successes, which were sufficient in number to justify the use of the treatment in these difficult cases, and, secondly, as a long term policy. It seemed probable that the fever in many cases acted as a stimulant to the immunity process and subsequent chemotherapy became effective although it had failed previously, for in so many of the cases in which there was immediate failure the ultimate result was satisfactory. That had been his experience with higher fever induced by mechanical means in which the results both in gonococcal and non-gonococcal cases had been excellent.

His own view was that this method of minor fever by means of T.A.B. vaccine, which was relatively so harmless should be used as soon as failure of the first course of sulphonamide had been recognised.

DR. FORGAN said that the term "sulphonamide resistant" was generally somewhat loosely used to describe cases that did not respond to a single course of drug treatment. Strictly speaking, a strain of organism was certainly drug-fast only if it grew on culture medium containing a considerable concentration of the chemical compound employed to treat the infection. It had been assumed that this resistance was attributable to the gonococcus, and not to the patient's tissues, and that intravenous injections of T.A.B. vaccine acted by breaking drug resistance. Was it not a more likely explanation that in such cases the body up to that time had failed to play its part in destroying the bacterial invaders? The vaccine stimulated tissue reaction and, thereafter, with further chemotherapy, cure was effected by the combined action of the sulphonamide and the tissues.

DR. D. ERskine expressed surprise that Capt. Nicol had so many as 207 such cases to report upon and he wondered what previous history and type of treatment applied to these cases; perhaps they had received the intensive treatment- 24 grammes in 48 hours! Most of the complications he had seen in the last eighteen months had been amongst service cases ; he had not seen many difficult cases in civilian clinics where, in acute cases, a dose of two $\frac{1}{2}$-gramme tablets of sulphapyridine had been given every 8 hours for 7 days with daily urethral irrigations. In the few difficult cases which had occurred, such as prostatitis, and occasionally arthritis, successful results were obtained with a combination of local treatment and intradermal gonococcal vaccine. He did not think subcutaneous vaccine was of any value in such cases, but intradermal vaccine coupled with local treatment of the infection at its focus had given very satisfactory results without making the patient ill or causing him to go into hospital. 


\section{BRITISH JOURNAL OF VENEREAL DISEASES}

LT.-CoL. KING said that the last speaker seemed to think that patients attending civil clinics did better than those in military hospitals. $\mathrm{He}$ was not in a position to give any comparative opinion, but when Dr. Erskine suggested that intensive dosage was productive of resistant cases he wondered whether such suggestion arose from impressions or supporting figures. Last year he and Major Williams reported almost identical results from intensive sulphapyridine therapy and from a moderate dosage for 14 days. Since then 500 cases had been treated with a Io-day course, 500 with a 7-day course and 500 with a 5-day course, again with almost identical results. He thought that Dr. Erskine would find that the intensity and duration of dosage were not the responsible factors.

Dr. ERSKINE thought that in the Army there was a tendency to give either short period intensive therapy or moderate doses of sulphapyridine for a week both being followed up by irrigations for a week. The results were probably less satisfactory than with maintained or the combined treatment respectively. The Army, having their patients completely under control, had the best opportunity for getting excellent results, and in his opinion the most satisfactory results would be obtained from the combined method using a smaller dosage.

The President, Col. L. W. Harrison, adverted to a paper by W. M. Simpson and colleagues in the BrITISH Journal of VenERAL DiSEASES for July/October I94I in which the author had claimed Ioo per cent. success with chemotherapy aided by pyrexia induced by the Kettering hypertherm. The impression one gained from a study of that paper was that the nearer one could approach the fever conditions obtained by its authors, the nearer one might get to the roo-per-cent.-cure ideal. Simpson et al. had obtained their best results by giving the sulphonamide preparation intensively for 18 hours before the fever, and that seemed also to have been Capt. Nicol's experience. On the strength of their results, Simpson et al. had suggested that the combination of fever and chemotherapy might be extended to more routine cases, not confined as hitherto to the resistant ones, and that brought one to the question of ways and means of making it more practicable for general application, a question which was, of course, bound up with that of safety. In connection with the question of safety, they had heard that afternoon the suggestion, with which he quite agreed, that perhaps T.A.B. vaccine was not the ideal vaccine for such work as this, although at the moment it might be the only one procurable. He had always preferred Dmelcos, as had been mentioned by other speakers, as the fever it produced did not seem to be accompanied by so much evidence of toxæmia, and that brought him to the work of Kulchar and Card (I94I Amer. J. Syph., 25, 466) to which Dr. Harkness had already referred. They had used for this purpose Typhoid $\mathrm{H}$ vaccine, made by adding to a 24-hour broth culture of typhoid bacilli 0.5 per cent. phenol and filtering, the filtrate containing flagella of typhoid bacilli. This vaccine they had found much less toxic than the ordinary variety and with its help they had been able to apply vaccine-fever to patients whose condition would have contra-indicated the use of T.A.B. vaccine. In the paper to which he had referred Kulchar and Card had reported on II 8 cases in which they claimed results comparable with those obtained by malarial treatment. They had used the double-dose 


\section{PYRETO-THERAPY}

method, and the temperatures achieved seem to have ranged from $104^{\circ} \mathrm{F}$. to $106^{\circ} \mathrm{F}$., apparently higher than those obtaining in Capt. Nicol's cases, and the return to normal had occupied from 6 to I 2 hours. He thought that, because of its apparently greater safety, the use of typhoid $\mathrm{H}$ vaccine for this purpose was well worth further study. $\mathrm{He}$ believed that, for cases under control, as was possible in the Services, this method had a future, and we were greatly indebted to Capt. Nicol for developing it at Netley and to the others who had worked along similar lines. From the practical point of view fever-plus-chemotherapy had possibilities in reduction of the duration of stay in hospital. Undoubtedly gonorrhœe was likely to increase, and any method which promised to reduce the occupation of beds by such cases was worthy of trial.

CAPT. NiCol, in reply, said that he felt that the divided dose was definitely better than the single dose method and that the toxic effects were in most cases very minor. The T.A.B. vaccine had been chosen because it was the most easily obtained: the Dmelcos vaccine was unobtainable.

Col. Harrison had mentioned that other workers had obtained higher temperature peaks than shown in this series. These, however, might have been rectal recordings. Also, it might have been possible to take the readings more frequently with, therefore, greater opportunity of recording the temperature peak which in some cases was very transient.

It is difficult to assess the clinical results in relation to the temperature reaction. The height and duration of the pyrexia were important but successes and failures were associated with either good or poor temperature reactions. The results did not depend entirely on the pyrexia.

The 207 cases, which seemed rather a large number, were practically all the resistant cases at Netley over a period of six months. The great majority were treated by a 7-day course of sulphapyridine, a few had a Io-days' course and some of the recent ones a 5-day course of $4 \frac{1}{2}$ grams daily.

He wondered whether Dr. Erskine had the same assessment of resistant cases as he had. In this paper he had recorded all cases which were not apparent cures after the first course of sulphapyridine as potentially resistant. Some of them were treated as resistant cases immediately with T.A.B. vaccine, others were treated further with other sulphonamides and irrigations. As far as irrigations were concerned, it was true that they were not used during the first week. He considered that it might be better to give T.A.B. vaccine immediately after the sulphapyridine and he hoped very soon to use the vaccine early in all cases which were not free from signs after a course of sulphapyridine. Certain of his cases had suggested, as speakers in the discussion had confirmed, that the T.A.B. vaccine did have some effect on the local tissue resistance and that subsequently sulphonamides would be effective.

On the question of cultures, Col. King had already mentioned that cultures had not been taken. Only a very few cases with gonococci persisting in the urethral smears were treated but there was some possibility in giving a fairly large dose of sulphapyridine and following on immediately with vaccine therapy. 


\section{BRITISH JOURNAL OF VENEREAL DISEASES}

This treatment, which after all was being done on the lines of higher fever therapy by mechanical means, was promising and he hoped that in the future it would be possible to treat a larger series of cases by this method.

\section{VIII \\ BOOK REVIEWS}

Common Skin Diseases. By A. C. Roxburgh, M.A., M.D.(Cantab), F.R.C.P. Sixth Edition. London: I94I. Messrs. H. K. Lewis $\&$ Co. Ltd., pp. 448 with I79 illustrations and 8 plates in colour. Price, I6s. net.

THE appearance of this new edition within two years indicates the popularity of the work, which offers a reasonable introduction to the more common diseases of the skin. Both the text and the index have been enlarged and the sections on treatment have been expanded in the light of recent progress. Dermatomyositis and Thorium $\mathrm{X}$ are considered in this new edition and the chapters on avitaminoses, impetigo, scabies and monilia infections have been rewritten and enlarged.

The text has been revised throughout and several minor modifications have been made. Treatment continues to be considered on conservative lines and dietary restrictions and internal remedies are not greatly favoured; Sulphonamide drugs are given credit for a certain limited therapeutic value. Reference is made to the use of the new emulsifying bases in dermatology, but a more detailed consideration would have been widely appreciated in view of the important advance in local treatment which they represent.

The wide incidence of scabies has been recognised and the chapter on this subject has been rewritten and much expanded; a clear description of the treatment is given and timely attention is drawn to the importance of the preliminary bathing and to terminal disinfestation. The choice of remedy is wisely shown to be of secondary importance, but a review of the newer as well as the time-honoured remedies is included.

A most valuable section of the book is the excellent Index of Preliminary Diagnoses which is retained; this indicates the sections of the text to which reference should be made in arriving at a probable diagnosis in a difficult case, while the supporting illustrations are of a high standard so that the volume will continue to be of considerable value to students and practitioners alike.

D. E.

Congenital Syphilis. By Charles C. Dennie, B.S., M.D., and Sidney F.

Pakula, B.S., M.D. With 133 engravings. Octavo, pp. 596. Published by Lea and Febiger, Philadelphia. Price $\$ 8.00$, net.

EDIToRs of scientific journals and reviewers, on reading monographs submitted to them for publication or review, must often wish that every 